\title{
Synthesis, Cytotoxicity, and Antileishmanial Activity of N,N'- Disubstituted Ethylenediamine and Imidazolidine Derivatives
}

\author{
Gustavo S.G. de Carvalho ${ }^{1, *}$, Patrícia A. Machado ${ }^{2, *}$, Daniela T.S. de Paula ${ }^{2, *}$, \\ Elaine S. Coimbra ${ }^{2}$, and Adilson D. da Silva ${ }^{1, * *}$ \\ ${ }^{1}$ Departamento de Química, I.C.E., Universidade Federal de Juiz de Fora, Cidade Universitária, Juiz \\ de Fora, Minas Gerais, Brasil; ${ }^{2}$ Departamento de Parasitologia, Microbiologia e Imunologia, I.C.B., \\ Universidade Federal de Juiz de Fora, Cidade Universitária, Juiz de Fora, Minas Gerais, Brasil \\ E-mail: senradcarvalho@yahoo.com.br; danielatsp@yahoo.com.br, patriciamachado12@yahoo.com.br; \\ elaine.coimbra@ufjf.edu.br; david.silva@ufjf.edu.br
}

Received May 12, 2010; Revised August 16, 2010; Accepted August 19, 2010; Published September 1, 2010

This paper describes the preparation of $\mathrm{N}^{\prime} \mathrm{N}^{\prime}$-disubstituted ethylenediamine and imidazolidine derivatives and their in vitro biological activities against Leishmania species. Of the nine synthesized compounds, five displayed a good activity in both $L$. amazonensis and $L$. major promastigotes. The compounds 1,2-Bis(p-methoxybenzyl) ethylenediamine (4) and 1,3-Bis(p-methoxybenzyl)imidazolidines $(\underline{5})$ showed the best activity on intracellular amastigotes, with $I_{50}$ values of 2.0 and $9.4 \mu \mathrm{g} / \mathrm{mL}$, respectively. In addition, none of compounds were cytotoxic against mammalian cells. The leishmanicidal activity can be related with inhibition of polyamine synthesis and cellular penetration within biological membranes.

KEYWORDS: imidazolidines; ethylenediamines; antileishmanial activity; Leishmania

\section{INTRODUCTION}

Leishmaniasis is a parasitic disease endemic in some tropical areas of the world and in underdeveloped countries, with an estimated 1.5 to 2 million cases per year[1]. It causes an estimated 70,000 deaths annually[1,2]. Chemotherapy against leishmaniasis in humans has been based on the pentavalent antimonials, such as sodium stibogluconate (Pentostam ${ }^{\circledR}$ ) and meglumine antimoniate (Glucantime $\left.{ }^{\circledR}\right)[1,2,3,4]$. These drugs induce toxic side effects that require lengthy treatments with parental administration and increasing resistance[3]. The second-line compounds used in unresponsive cases include pentamidine and amphotericin $B$, but these drugs are very toxic $[1,2,3,4]$.

An interesting chemotherapeutic approach in the design of novel antiparasitic drugs is the inhibition of parasitic biosynthesis of polyamines[5,6,7]. The hydrophobic moiety chains could interact with membrane lipids, facilitating the penetration of the drug into the cytoplasm where it interferes with the polyamine metabolism pathway of the parasite[5,6,7,8]. Additionally, due to the hydrophobic nature of 
imidazolidines, they were employed as ethylenediamine carriers. Recently, various derivatives of polyamines with antiparasitic activity have been introduced[9,10,11,12].

Imidazolidines, cyclic aminals of pharmacological interest, as well as N,N'-dibenzyl-2arylimidazolidines, N,N'-bisaminoalkylimidazolidines, and N,N-dihydroxyphenylimidazolidines have shown fungicidal, antiparasitic, antibacterial, antiamebic, and antiviral activities[13,14]. Encouraged by this observation, the present paper describes the preparation of N,N'-disubstituted ethylenediamine and imidazolidine derivatives (Scheme 1) and their in vitro biological activities against Leishmania promastigote and amastigote forms. These types of compounds can be considered able to interact with membrane lipids, to be transported into the cytoplasm, and, possibly, to interfere with the lipid or polyamine transport or metabolism of the parasite $[5,6,15,16,17]$.

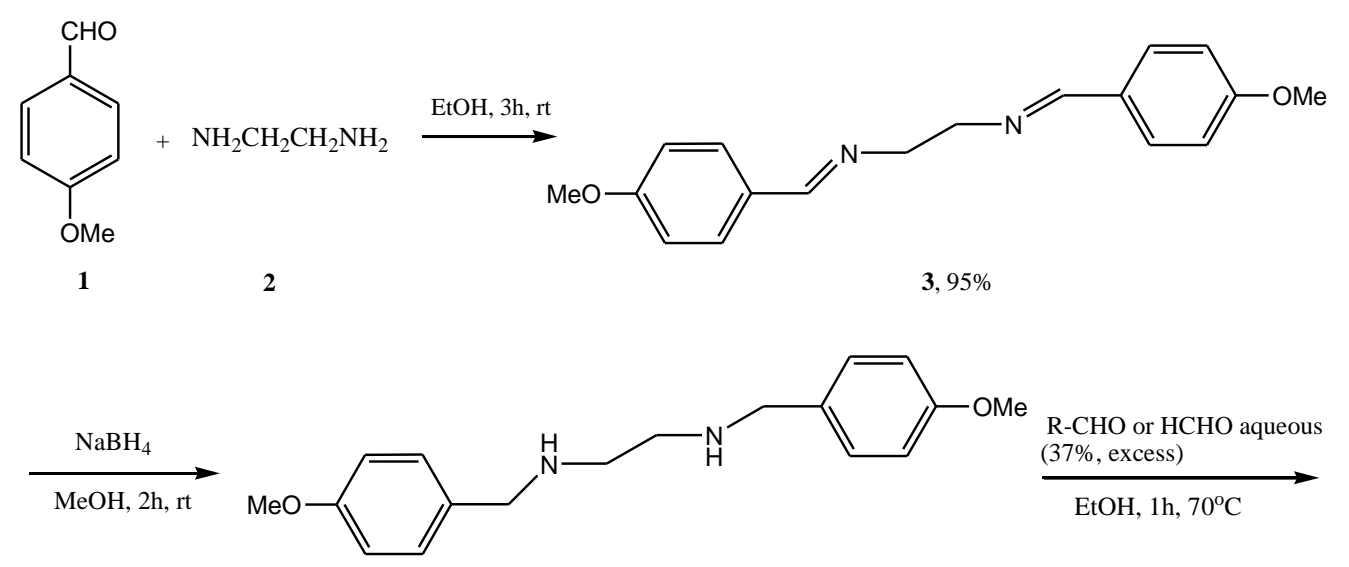

4, $80 \%$
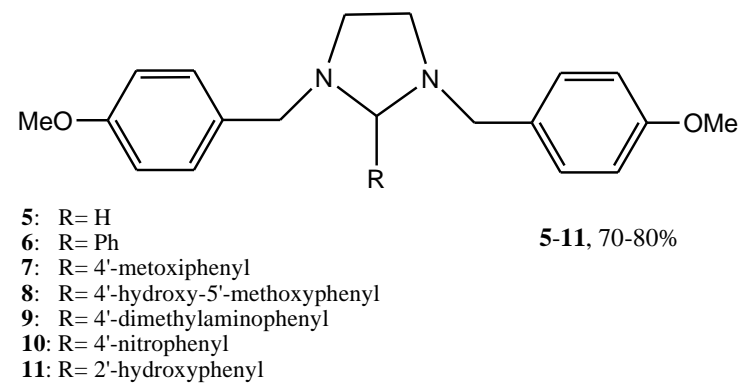

SCHEME 1. Reagents and conditions: (a) EtOH, 3h, rt; (b) $\mathrm{NaBH}_{4}, \mathrm{MeOH}, 2 \mathrm{~h}, \mathrm{rt}$; (c) aldehydes or aqueous formaldehyde (37\%, excess), $\mathrm{EtOH}, 1 \mathrm{~h}, 70^{\circ} \mathrm{C}$.

\section{MATERIALS AND METHODS}

\section{Chemicals}

The imidazolidine derivatives $\mathbf{5}-\mathbf{1 1}$ were synthesized by the classical method involving condensation between N,N'-disubstituted ethylenediamine $\mathbf{4}$ with a variety of aromatic aldehydes in EtOH (Scheme 1). $\mathrm{N}, \mathrm{N}^{\prime}$-disubstituted ethylenediamine precursors were prepared following procedures in the literature. Those having benzyl substituents were synthesized by condensation of ethylenediamine $\mathbf{2}$ with aromatic aldehydes 1, described previously[19], and further reduction of the generated Schiff bases with sodium borohydride, $70-80 \%$ yield[20]. All compounds were characterized by melting point (m.p.), ${ }^{1} \mathrm{H}$ and ${ }^{13} \mathrm{C}$ NMR (Table 1), and were in accordance with data in the literature[13,14,18]. 
TABLE 1

Spectral Dates of Imidazolidine Derivatives

\begin{tabular}{lcccc}
\hline Compound & $\boldsymbol{\delta} \mathbf{C} \underline{\mathbf{H}}-(\mathbf{N})_{\mathbf{2}}$ & $\boldsymbol{\delta} \underline{\boldsymbol{C}}-(\mathbf{N})_{\mathbf{2}}$ & M.P. ( $\left({ }^{\circ} \mathbf{C}\right)$ & Yield $(\%)$ \\
\hline $\mathbf{5}$ & $5.39(\mathrm{~s}, 2 \mathrm{H})$ & 75.8 & Semisolid & 76 \\
$\mathbf{6}$ & $3.72(\mathrm{~s}, 1 \mathrm{H})$ & 89.1 & 92.0 & 74 \\
$\mathbf{7}$ & $3.68(\mathrm{~s}, 1 \mathrm{H})$ & 88.6 & $75.0-77.2$ & 70 \\
$\mathbf{8}$ & $3.70(\mathrm{~s}, 1 \mathrm{H})$ & 88.9 & $104.7-106.5$ & 75 \\
$\mathbf{9}$ & $3.75(\mathrm{~s}, 1 \mathrm{H})$ & 88.9 & $111.4-112.8$ & 76 \\
$\mathbf{1 0}$ & $3.94(\mathrm{~s}, 1 \mathrm{H})$ & 87.7 & $150.3-150.7$ & 74 \\
$\mathbf{1 1}$ & $3.93(\mathrm{~s}, 1 \mathrm{H})$ & 88.9 & $121.9-133.3$ & 79 \\
\hline
\end{tabular}

The experiments were performed at $300 \mathrm{MHz}$ for ${ }^{1} \mathrm{H}$ and $75 \mathrm{MHz}$ for ${ }^{13} \mathrm{C}$ in $\mathrm{CDCl}_{3}$ and TMS as internal reference $(\delta 0.00 \mathrm{ppm})$.

\section{Biological Assays}

Stock solutions of compounds were prepared at a concentration of $120 \mathrm{mg} / \mathrm{mL}$ in dimethyl sulfoxide (DMSO) and were kept frozen at $-20^{\circ} \mathrm{C}$. Amphotericin B was supplied by Cristália (São Paulo, Brazil), prepared as a $10-\mathrm{mg} / \mathrm{mL}$ stock solution in Millipore water. Working solutions of compounds were prepared fresh for each use, by serial dilution of the stock solutions in Millipore water. Fetal bovine serum (FBS) was purchased from Cultilab (Campinas, São Paulo, Brazil). Brain heart infusion (BHI) was purchased from Himédia (Mumbai, India). Hemin, folic acid, RPMI 1640 medium, 3-(4,5dimethylthiazol-2-yl)-2,5-diphenyl-tetrazolium bromide (MTT), and DMSO were purchased from Sigma Chemical (St. Louis, MO).

\section{In vitro Antileishmanial Activity}

- Promastigote forms - For this assay, promastigotes of L. amazonensis (IFLA/Br/67/PH8) and $L$. major (MRHO/SU/59/P) were used. Promastigotes of L. amazonensis were cultured in Warren's medium (BHI, plus hemin and folic acid)[20] and promastigotes of L. major were maintained in medium BHI[21], both supplemented with $10 \%$ inactivated $\mathrm{FBS}$ at $24^{\circ} \mathrm{C}$. Log phase promastigotes of two Leishmania species were seeded in 96-well tissue culture plates $\left(2 \times 10^{5}\right.$ cells/well). The parasites were exposed to increased concentrations of the compounds (at minimum six serial dilutions) for $72 \mathrm{~h}$ at $24^{\circ} \mathrm{C}$ and their viability was evaluated using a MTT assay, as described previously[22]. Amphotericin B was used as positive control. Controls containing $0.5 \%$ DMSO and medium alone were also included. The results are expressed as the concentrations inhibiting parasite growth by $50 \%\left(\mathrm{IC}_{50}\right)$.

- Amastigote forms - Concerning the amastigotes in vitro model, macrophages were obtained from BALB/c mice previously inoculated with 3\% thioglycolate medium[23]. Briefly, peritoneal macrophages were plated at $2 \times 10^{5}$ cells per well on coverslips (13-mm diameter) previously arranged in a 24-well plate in RPMI 1640 medium supplemented with 10\% inactivated FBS and allowed to adhere for $24 \mathrm{~h}$ at $37^{\circ} \mathrm{C}$ in $5 \% \mathrm{CO}_{2}$. Adherent macrophages were infected with $L$. amazonensis (IFLA/Br/67/PH8) promastigotes in the stationary growth phase using a ratio of 1:5 at $37^{\circ} \mathrm{C}$ for $3 \mathrm{~h}$. Noninternalized promastigotes were eliminated and solutions of tested compounds were added (nonserial five dilutions: from 45 to $1.5 \mu \mathrm{g} / \mathrm{mL}$ for compounds $\mathbf{4}$ and 5; from 60 to $2.0 \mu \mathrm{g} / \mathrm{mL}$ for compounds $\mathbf{6}, 7$, and 11). Then, the cells were maintained at $37^{\circ} \mathrm{C}$ in $5 \% \mathrm{CO}_{2}$ for $72 \mathrm{~h}$, fixed, and stained with Giemsa for parasite counting (optical microscopy, 
$1000 \times$ magnification). The survival index was obtained by multiplying the percentage of infected macrophages by the mean number of amastigote forms per infected cell[24]. Amphotericin B was used as the reference drug.

\section{Cytotoxicity against Mammalian Cells}

Mouse peritoneal macrophages were used for cytotoxicity assay. The cells were incubated with compounds in a sixfold dilution from 30.0 to $2.0 \mu \mathrm{g} / \mathrm{mL}$ (for compounds 3-5) and from 40.0 to $2.0 \mu \mathrm{g} / \mathrm{mL}$ (for compounds 6-11), in triplicate at each concentration. The viability of the macrophages was determined with the MTT assay and was confirmed by comparing the control group morphology via light microscopy[21].

\section{Statistical Analysis}

For promastigote forms of Leishmania assay and cytotoxicity on macrophages, the $\mathrm{IC}_{50}$ values were carried out at 5\% significance level ( $p<0.05$, CI 95\%), calculated using a nonlinear regression curve, by using GraFit Version 5 software (Erithacus Software, Horley, U.K). For Leishmania amastigote assays, the statistical analysis was performed with the program GraphPad Prism 4 (GraphPad Software, San Diego, CA). One-way ANOVA was applied to compare all the groups. To compare the control with each compound, concentration was applied Dunnett post-test. Differences were regarded as significant when $p$ $<0.0001(* * *)$ and $p<0.001(* *)$.

\section{RESULTS AND DISCUSSION}

In the present study, the imidazolidine derivatives were screened for their cytotoxicity against Leishmania and macrophages.

The antiproliferative activity of compounds 3-11 against L. amazonensis and L. major promastigote forms are described in Table 2. The results are expressed as the concentrations inhibiting parasite growth by $50 \%\left(\mathrm{IC}_{50}\right)$. The ethylenediamine derivative 4 , with a free amino group, and compounds $\mathbf{5 , 6}, \mathbf{7}$, and 11 showed the best antiproliferative activities against L. amazonensis and L. major. Compound $\mathbf{4}$ showed the highest activity against the two Leishmania species. In this series, compound $\mathbf{9}$ also displayed good in vitro activity against $L$. major promastigote forms. In general, $L$. major promastigotes were the most sensitive to the compounds tested. Compounds $\mathbf{3 ,} \mathbf{8}$, and $\mathbf{1 0}$ did not show activity against promastigote forms of Leishmania species. Amphotericin B, used as the reference drug, showed $\mathrm{IC}_{50}$ values of 0.4 and $0.3 \mu \mathrm{g} / \mathrm{mL}$ on L. amazonensis and L. major promastigote forms, respectively.

In this work, two Leishmania species were used and the results reflect differences in sensitivity of these parasites to the compounds tested. This fact is not surprising and previous in vitro studies have shown differences in sensitivity of Leishmania species in different classes of drugs[23,25,26].

For cytotoxicity on macrophages, none of the compounds tested were shown to be toxic to mammalian cells in the maximum concentration tested (Table 2).

The L. amazonensis-infected BALB/c macrophage model was assayed, aiming to confirm the activity of the imidazolidine derivatives against the intracellular stage of the parasite[1,2,4]. In this series, compounds 4, 5, 6, 7, and 11 were selected because of their high activity against Leishmania promastigotes and their low toxicity against murine macrophages (Fig. 1). When the parasites were treated with the compounds, a significant dose-dependent decrease of intracellular amastigotes was observed. All compounds showed a significant effect against the amastigote forms of L. amazonensis. Compounds 4 and $\mathbf{5}$ showed the best activity on intracellular amastigotes, with an $\mathrm{IC}_{50}$ value of 2.0 and $9.4 \mu \mathrm{g} / \mathrm{mL}$, respectively. For compounds 4 and 5, the survival index was calculated as 2.2 and 0.0 for 45 
TABLE 2

Effect of the Compounds 3-11 against $L$. amazonensis and $L$. major Promastigote Forms and Murine Macrophages

\begin{tabular}{|c|c|c|c|}
\hline \multirow{2}{*}{ Compounds } & \multicolumn{3}{|c|}{$\mathrm{IC}_{50}(\mu \mathrm{g} / \mathrm{mL})$} \\
\hline & L. amazonensis ${ }^{a}$ & L. major & Peritoneal Macrophages $^{a}$ \\
\hline 3 & $>30.0$ & $>30.0$ & $>30.0$ \\
\hline 4 & 1.9 & 1.8 & $>30.0$ \\
\hline 5 & 4.7 & 2.4 & $>30.0$ \\
\hline 6 & 13.6 & 4.0 & $>30.0$ \\
\hline 7 & 9.0 & 3.0 & $>40.0$ \\
\hline 8 & $>40.0$ & $>40.0$ & $>40.0$ \\
\hline 9 & $>40.0$ & 8.6 & $>40.0$ \\
\hline 10 & $>40.0$ & $>40.0$ & $>40.0$ \\
\hline 11 & 12.4 & 6.7 & $>40.0$ \\
\hline
\end{tabular}

$\mu \mathrm{g} / \mathrm{mL}, 12.6$ and 2.7 for $30 \mu \mathrm{g} / \mathrm{mL}, 15.7$ and 17.8 for $15 \mu \mathrm{g} / \mathrm{mL}, 16.6$ and 132.78 for $7.5 \mu \mathrm{g} / \mathrm{mL}$, and 300.0 and 323.5 for $1.5 \mu \mathrm{g} / \mathrm{mL}$, respectively. These results correspond to an inhibition of survival index of 99.6, 98.0, 97.5, 97.0, and 55.0\%, respectively, for compound 4, and 100.0, 99.6, 97.0, 80.0, and $51.3 \%$, respectively, for compound 5. Amphotericin B, the reference drug, inhibited $63.1 \%$ of amastigotes in $5 \mu \mathrm{g} / \mathrm{mL}$ in $72 \mathrm{~h}$ after treatment.

\section{CONCLUSION}

In summary, this work describes the synthesis and leishmanicidal activity of ethylenediamine and imidazolidine derivatives. The compounds showed a good activity against Leishmania without cytotoxicity on macrophages at the maximum concentration tested. Five compounds (4-7 and 11) displayed a good activity on promastigote forms of Leishmania species. Compounds $\mathbf{4}$ and $\mathbf{5}$ showed the best activity against $L$. amazonensis amastigote forms, indicated by the greater reduction in survival indices of parasites. In general, the addition of an aromatic substituent in position 2 of the imidazolidine ring decreased the antileishmanial activity. The biological activity shown by compound $\mathbf{4}$ coincides with the presence of the group ethylenediamine in the structure that interferes with the polyamine metabolism[5,6,7,8]. On the other hand, the less polar substitution in position 2 of the imidazolidine ring (compound 5) suggests that the compound has a good cellular penetration across biological membranes.

\section{ACKNOWLEDGMENTS}

The authors gratefully acknowledge UFJF, CAPES, and CNPq for fellowships. This research was supported by FAPEMIG. 

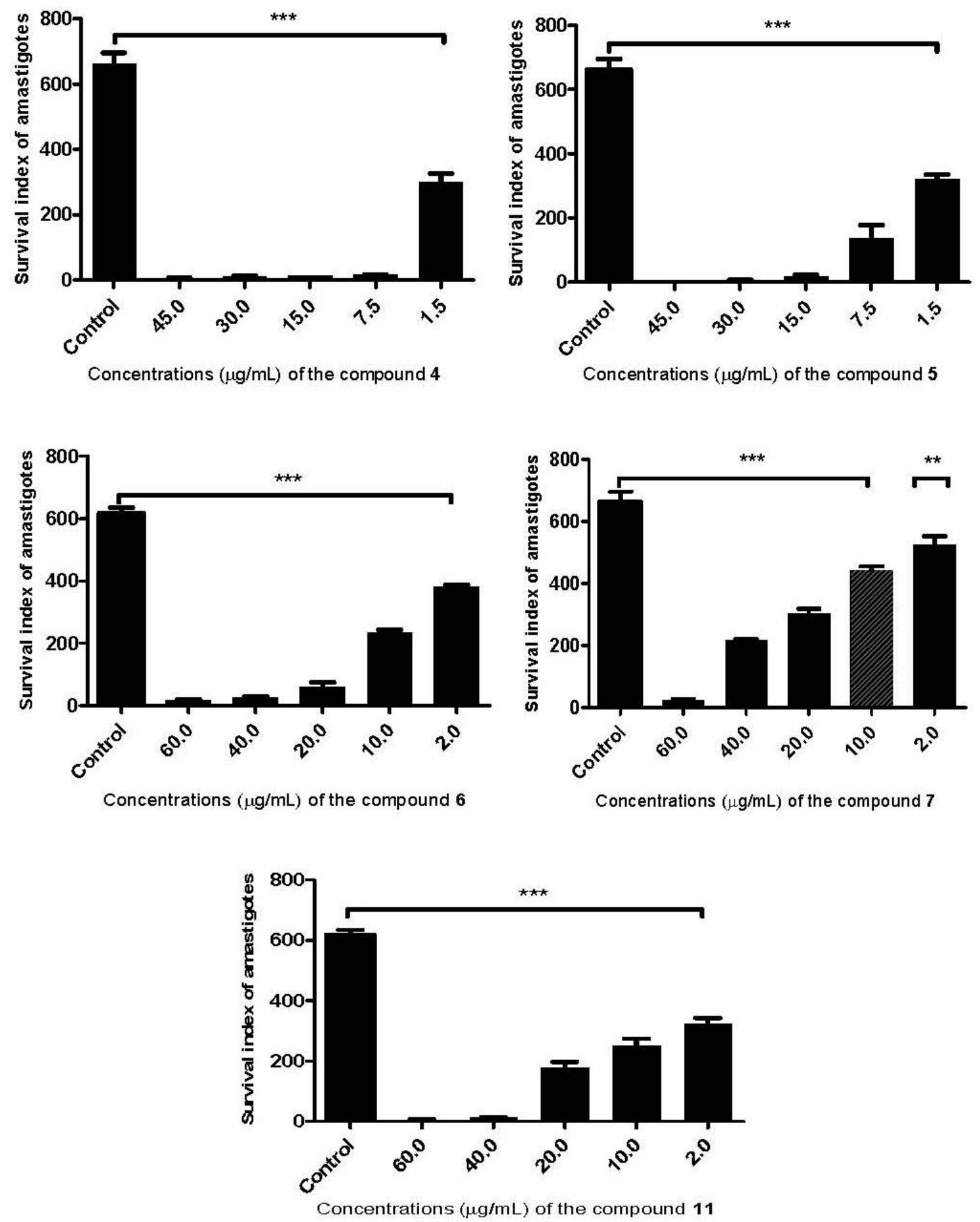

FIGURE 1. Effect of the imidazolidine derivatives on L. amazonensis interiorized in peritoneal macrophage cells. Statistically significant difference of control: $* * p<0.001 ; * * * p<0.0001$.

\section{REFERENCES}

1. Santos, D.O., Coutinho, C.E., Madeira, M.F., Bottino, C.G., Vieira, R.T., Nascimento, S.B., Bernardino, A., Bourguignon, S.C., Corte-Real, S., Pinho, R.T., Rodrigues, C.R., and Castro, H.C. (2008) Leishmaniasis treatment - a challenge that remains: a review. Parasitol. Res. 103, 1-10. 
2. Cruz, A.K, De Toledo, J.S., Falade, M., Terrão, M.C., Kamchonwongpaisan, S., Kyle, S., and Uthaipibull, C. (2009) Current treatment and drug discovery against Leishmania spp. and Plasmodium spp.: a review. Curr. Drug Targets 10, 178-192.

3. Singh, R.K., Pandey, H.P., and Sundar, S. (2006) Visceral leishmaniasis (kala-azar): challenges ahead. Indian J. Med. Res. 123, 331-344.

4. Vieira, N.C., Herrenknecht, C., Vacus, J., Fournet, A., Bories, C., Figadère, B., Espindola, L.S., and Loiseau, P.M. (2008) Selection of the most promising 2-substituted quinoline as antileishmanial candidate for clinical trials. Biomed. Pharmacother. 62, 684-689.

5. Del Olmo, E., Alves, M., Lopéz, J.L., Inchaustti, A., Yaluff, G., De Arias, A.R., and San Feliciano, A. (2002) Leishmanicidal activity of some aliphatic diamines and amino-alcohols. Bioorg. Med. Chem. Lett. 12, 659-662.

6. Rebollo, O., Del Olmo, E., Ruiz, G., Lopéz, J.L., Giménez, A., and San Feliciano, A. (2008) Leishmanicidal and trypanocidal activities of 2-aminocyclohexanol and 1,2-cyclohexanediamine derivatives. Bioorg. Med. Chem. Lett. 18, 184-187.

7. Bacchi, C.J. and Yarlett, N. (2002) Polyamine metabolism as chemotherapeutic target in protozoan parasites. Mini Rev. Med. Chem. 2, 553-563.

8. Casero, R.A., Jr. and Woster, P.M. (2001) Terminally alkylated polyamine analogues as chemotherapeutic agents. $J$. Med. Chem. 44, 1-26.

9. Nieper, H.A. (1966) Experimental tests of new carcinostatic compounds in HeLa cells. Arztl. Forsch. $20,18-21$.

10. Schoenenberger, H., Adam, A., and Adam, D. (1966) The action of aminomethylating carcinostatics on experimental tumors. Arztl. Forsch. 16, 734-738.

11. Coimbra, E.S., Almeida, C.G., Júnior, W.V., Dos Reis, R.C., De Almeida, A.C., Forezi, L.S., De Almeida, M.V., and Le Hyaric, M. (2008) Antileishmanial activity of aldonamides and $\mathrm{N}$-acyl-diamine derivatives. TheScientificWorldJOURNAL. 8,752-756.

12. Da Costa, C.F., Coimbra, E.S., Braga, F.G., dos Reis, R.C., da Silva, A.D., and de Almeida, M.V. (2009) Preparation and antileishmanial activity of lipophilic N-alkyl diamines. Biomed. Pharmacother. 63, 40-42.

13. Caterina, M.C., Perillo, I.A., Boiani, L., Pezaroglo, H., Cerecetto, H., González, M., and Salerno, A. (2008) Imidazolidines as new anti-Trypanosoma cruzi agents: biological evaluation and structure-activity relationships. Bioorg. Med. Chem. 16, 2226-2234.

14. Sharma, V. and Khan, M.S. (2001) Synthesis of novel tetrahydroimidazole derivatives and studies for their biological properties. Eur. J. Med. Chem. 36, 651-658.

15. Herrmann, H.O. and Gercken, G. (1982) Metabolism of 1-0-[1'-14C]octadecyl-sn-glycerol in Leishmania donovani promastigotes. Ether lipid synthesis and degradation of the ether bond. Mol. Biochem. Parasitol. 5, 65-76.

16. Basselin, M. and Robert-Gero, M. (1998) Alterations in membrane fluidity, lipid metabolism, mitochondrial activity, and lipophosphoglycan expression in pentamidine-resistant Leishmania. Parasitol. Res. 84, 78-83.

17. Heby, O., Roberts, S.C., and Ulman, B. (2003) Polyamine biosynthetic enzymes as drug targets in parasitic protozoa. Biochem. Soc. Trans. 31, 415-419.

18. Billman, J.H., Chen Ho, J.Y., and Caswell, L.R. (1952) The formation of solid derivatives of aldehydes. I. 2Substituted-1,3-Bis(p-methoxybenzyl)-tetrahydroimidazoles. J. Org. Chem. 17, 1375-1378.

19. General procedure: 1,2-Bis(p-methoxybenzylidene)ethylenediamine 3. Ethylenediamine $(0.05$ mol) was added at a solution of anisaldehyde $(0.1 \mathrm{~mol})$ in absolute ethanol $(30 \mathrm{~mL})$ then stirred for $4 \mathrm{~h}$ at room temperature. The white crystal precipitate was filtered, washed with water and ethyl ether giving the compound $\mathbf{3}$ in $95 \%$ yield; m.p. 111$112^{\circ} \mathrm{C}$ (lit. $\left.110-111^{\circ} \mathrm{C}\right)^{19},{ }^{1} \mathrm{H}$ NMR $\left(300 \mathrm{MHz}, \mathrm{CDCl}_{3}\right), \delta(\mathrm{ppm}), J(\mathrm{~Hz}): 3.81\left(\mathrm{~s}, 6 \mathrm{H}, 2 \mathrm{CH}_{3}, \mathrm{MeOPh}\right), 3.91(\mathrm{~s}, 4 \mathrm{H}$, $\left.2 \mathrm{CH}_{2}\right), 6.89(\mathrm{~d}, 4 \mathrm{H}, 4 \mathrm{CH}, J=8), 7.64(\mathrm{~d}, 4 \mathrm{H}, 4 \mathrm{CH}, J=8.5), 8.20(\mathrm{~s}, 2 \mathrm{H}, 2 \mathrm{CH}$, imine $)$. 1,2-Bis(pmethoxybenzyl)ethylenediamine 4 . The compound $3(0.05 \mathrm{~mol})$ was dissolved in methanol $(40 \mathrm{~mL})$ and then a solution of sodium borohydride $(0.05 \mathrm{~mol})$ in distillated water $(10 \mathrm{~mL})$ was added dropwise to the methanolic solution of compound 3 with stirring under cold bath. After TLC (dichloromethane/methanol 9:1) showed the completion of the reaction, the solvent was distilled off and the residue was dissolved in dichloromethane and washed with brine. The organic layer was dried over sodium sulfate, filtered, and evaporated, giving the semi-solid compound 4, 80\% yield; ${ }^{1} \mathrm{H}$ NMR $\left(300 \mathrm{MHz}, \mathrm{CDCl}_{3}\right), \delta(\mathrm{ppm}), J(\mathrm{~Hz}): 2.34$ (sl, $2 \mathrm{H}, \mathrm{H}$ amine), $2.66\left(\mathrm{~s}, 4 \mathrm{H}, 2 \mathrm{CH}_{2}\right), 3.62\left(\mathrm{~s}, 4 \mathrm{H}, 2 \mathrm{CH}_{2}\right)$, $3.67\left(\mathrm{~s}, 6 \mathrm{H}, 2 \mathrm{CH}_{3}, \mathrm{MeOPh}\right), 6.89(\mathrm{~d}, 4 \mathrm{H}, 4 \mathrm{CH}, J=8), 7.64(\mathrm{~d}, 4 \mathrm{H}, 4 \mathrm{CH})$. 2-Substituted-1,3-Bis(pmethoxybenzyl)imidazolidines 5-11. Imidazolidine derivatives were obtained by reaction of the compound $4(0.01$ mol) and aldehydes $(0.01 \mathrm{~mol})$ or aqueous formaldehyde $\left(37 \%\right.$, excess) in ethanol $(10 \mathrm{~mL})$ under $70^{\circ} \mathrm{C} \mathrm{by} 1 \mathrm{~h}$. Compounds 6-11 were precipitated by cooling the mixture. Compound 5 was obtained by extraction in oil form.

20. Warren, L.G. (1960) Metabolism of Schizotrypanum cruzi Chagas. I. Effect of culture age and substrate concentration on respiratory rate. J. Parasitol. 46, 529-539.

21. Rodrigues, F.H., Afonso-Cardoso, S.R., Gomes, M.A.B., Beletti, M.E., Rocha, A., Guimarães, A.H.B., Candeloro, I., and de Souza, M.A. (2006) Effect of imidocarb and levamisole on the experimental infection of BALB/c mice by Leishmania (Leishmania) amazonensis. Vet. Parasitol. 139, 37-46.

22. MBongo, N., Loiseau, P.M., Lawrence, F., Bories, C., Craciunescu, D.G., and Robert-Gero, M. (1997) Synergistic effect of Ir-(COT)-pentamidine alizarin red and pentamidine, amphotericin B, and paromomycin on Leishmania donovani. Acta Trop. 70, 239-245. 
23. Morais-Teixeira, E., Carvalho, A.S., Costa, J.C.S., Duarte, S.L., Mendonça, J.S., Boechat, N., and Rabello, A. (2008) In vitro and in vivo activity of meglumine antimoniate produced at Farmanguinhos-Fiocruz, Brazil, against Leishmania (Leishmania) amazonensis, L (L.) chagasi and L (Viannia) braziliensis. Mem. Inst. Oswaldo Cruz 103, 358-362.

24. Santos, A.O., Ueda-Nakamura, T., Dias Filho, B.P., Veiga Junior, V.F., Pinto, A.C., and Nakamura, C.V. (2008) Effect of Brazilian copaiba oils on Leishmania amazonensis. J. Ethnopharmacol. 120, 204-208.

25. Braga, F.G., Coimbra, E.S., de Oliveira Matos, M., Lino Carmo, A.M., Cancio, M.D., and da Silva, A.D. (2007) Synthesis and biological evaluation of some 6-substituted purines. Eur. J. Med. Chem. 42, 530-537.

26 Escobar, P., Matu, S., Marques, C., and Croft, S.L. (2002) Sensitivities of Leishmania species to hexadecylphosphocholine (miltefosine), ET-18-OCH(3) (edelfosine) and amphotericin B. Acta Trop. 81, 151-157.

\section{This article should be cited as follows:}

de Carvalho, G.S.G., Machado, P.A., de Paula, D.T.S., Coimbra, E.S., and da Silva, A.D. (2010) Synthesis, cytotoxicity, and antileishmanial activity of N,N'-disubstituted ethylenediamine and imidazolidine derivatives. TheScientificWorldJOURNAL 10, 1723-1730. DOI 10.1100/tsw.2010.176. 

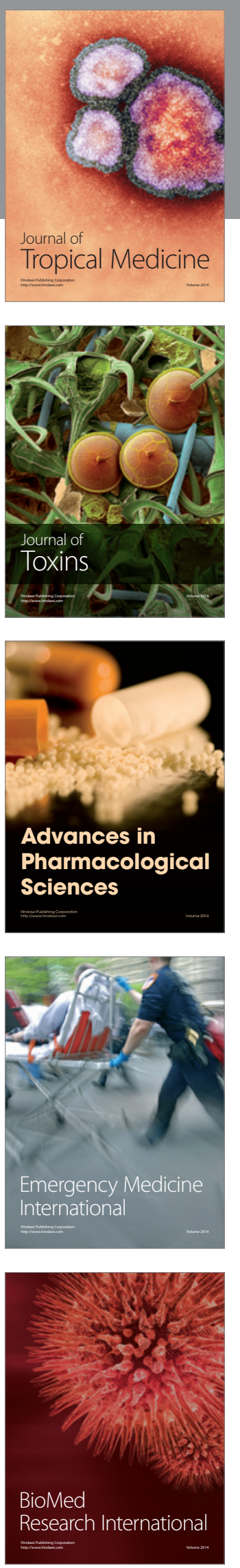
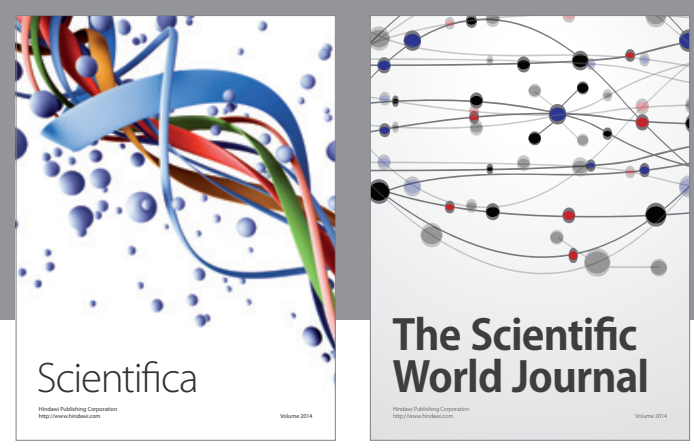

The Scientific World Journal
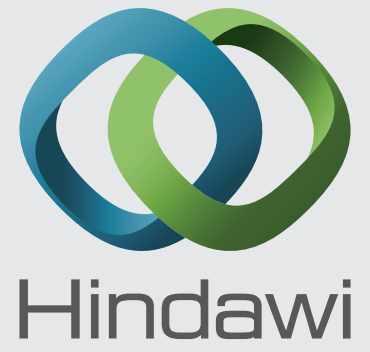

Submit your manuscripts at

http://www.hindawi.com
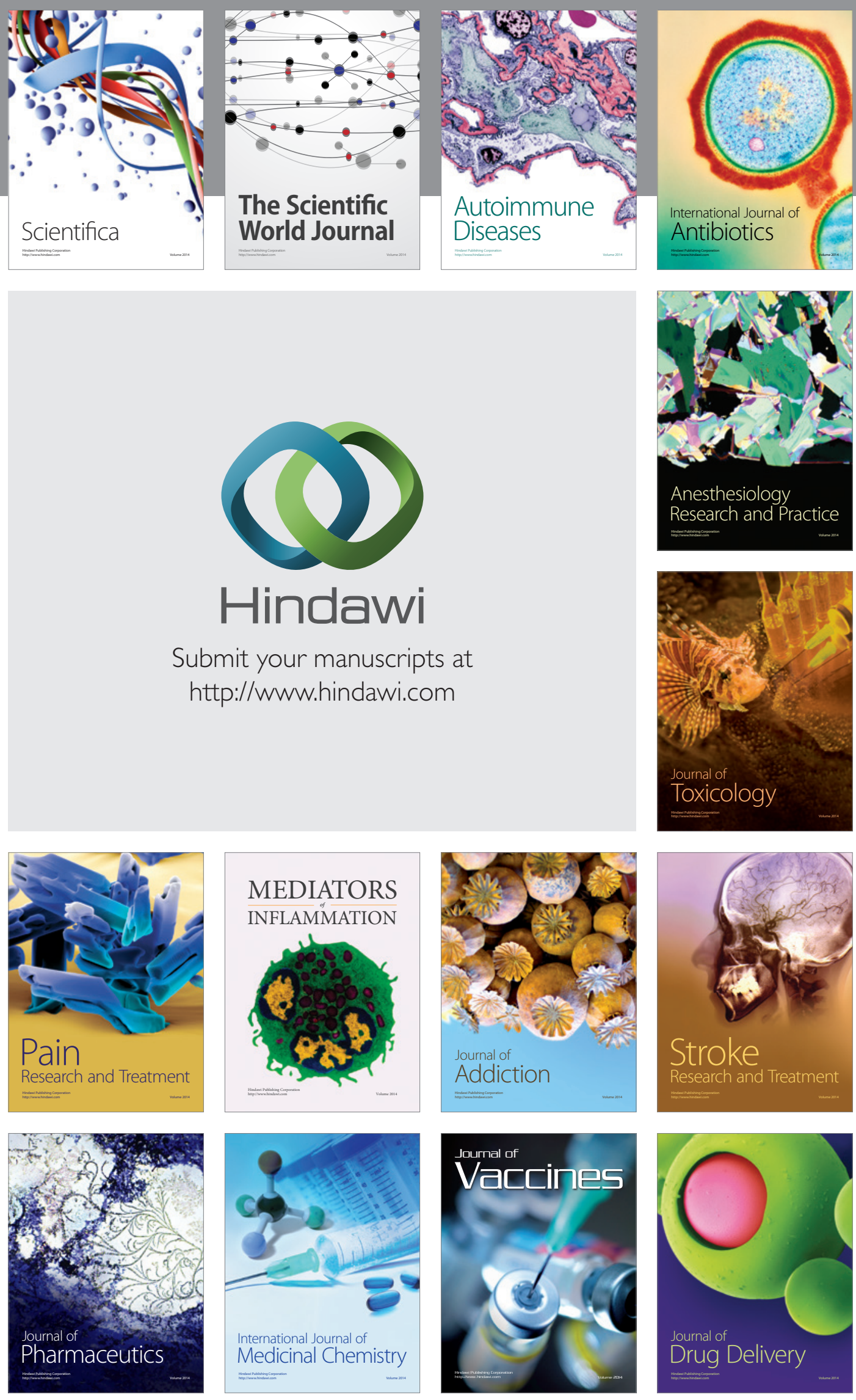